\title{
Vigiando manifestações de juventude 0 caso da antologia Novíssimo teatro português (1962)
}

\author{
Rui Pina Coelho
}

Maria Teresa Horta, em entrevista ao autor deste

artigo, recorda qu também Jaime Salazar

Sampaio estaria numa na

lista de hipotéticos colaboradores, mas que

não lhe era possivel na

altura; contudo, este sería incluido numa antologia

de propósitos similares

compilada por Artur Portela, José Sasportes Artur Ramos, com textos de Salazar Sampaio (Nos jardins de Alto Maior)

Teresa Rita Lopes (Três fósforos) e Artur Portela (A rotativa), publicada em 1962, intitulada Teatro 62,

Guimarães Editores (Lisboa); e Jaime Salazar

Sampaio aparecerá

também no volume Teatro de novos, com peças deste (O pescador à linha)

e de Augusto Sobral

( 0 consultório).
As encenações, frequentemente espantosas, da dramaturgia moderna nas décadas de 1950 e 1960 foram substituídas, em Portugal, por uma discreta mise-en-anthologie. Já que muitos autores e títulos eram simplesmente proibidos, as páginas substituiam os palcos. Jovens amadores de teatro, críticos, professores, escritores, poetas, intelectuais, todos aspiravam a criar um reportório para o futuro. Mas, uma vez que as mais recentes inovações teatrais provenientes do resto da Europa não conseguiam chegar aos palcos, os fazedores de teatro "antologizavam" as suas aspirações. Com este acto, mais do que prestarem uma justa homenagem ao passado e aos seus representantes, olhavam corajosamente para o futuro.

A antologia Novissimo teatro portuquês (1962) é um desses exemplos que davam voz a algum do descontentamento no pós-guerra português. Trata-se de uma colecção de cinco curtas peças, seleccionadas por Ilídio Ribeiro (um homem de negócios e um intelectual): O general, de Artur Portela Filho; O borrão, de Augusto Sobral; O museu, de Fiama Hasse Pais Brandão; Funerais, de José Estevão Sasportes; e 0 delator, de Maria Teresa Horta. Esta antologia, inevitavelmente jovem e subversiva foi surpreendentemente prefaciada pelo reputado (e frequentemente censurado) dramaturgo Bernardo Santareno. A colectânea, ainda que tivesse um eco discreto, cedo representaria um gesto de esperança num teatro que tardava em chegar. Importa, por isso, discutir o papel desta antologia de teatro na árdua tarefa de renovação cénica em Portugal.

0 volume foi encomendado e pago por llídio Ribeiro publicada em 1962, na editora Ao Sol. A sua publicação é consequência do entusiasmo criado por uma outra antologia: Poesia 61, uma selecção de poemas e, consequentemente, um movimento constituido por jovens poetas, tais como Casimiro de Brito, Luiza Neto Jorge, Gastão Cruz, Fiama Hasse Pais Brandão e Maria Teresa Horta. Estes revolucionaram a poesia portuquesa da década de sessenta, combinando as mais experimentais explorações da linguagem com um voraz comentário político e social. Dito isto, esta antologia de poesia é ainda considerada um dos momentos mais importantes da literatura portuguesa e um dos mais influentes movimentos da segunda metade do século. De Novissímo teatro português era esperado que se inscrevesse na mesma onda de renovação e que tivesse o mesmo impacto na cena teatral. Fiama Hasse Pais Brandão (1938-2007) e Maria Teresa Horta (n. 1937) apareciam nas duas antologias; e llidio Ribeiro seleccionou também textos de Artur Portela Filho (n. 1937), Augusto Sobral (n.1933) e José Sasportes (n. 1937) Não constituiam um grupo nem tão pouco se encontravam regularmente. ${ }^{1}$

Todos os cinco seleccionados eram jovens autores que se aventuravam na escrita dramática. Artur Portela (com 24 anos) era, na altura, um jornalista cultural, dirigindo suplementos literários e periódicos como Vida literária ou Europa, publicando vários títulos de contos ou de crónicas, tais como A feira das vaidades, em 1959, imediatamente apreendida pela PIDE pelo seu carácter subversivo. Em 1963, Artur Portela seria o tradutor de Depoimentos dos "Angry Men" (Declarations), um volume com testemunhos de John Osborne, Colin Wilson, John Wain, Doris Lessing, Kenneth Tynan, Bill Hopkins, Lindsay Anderson e Stuart Holroyd. Na contra-capa do volume, os editores sentiram a necessidade de avisar:

\footnotetext{
0 que resulta deste conjunto de ensaios (...) é, muito mais que a simples cólera de uns quantos jovens em guerra contra uma tradição literária, o seu carácter de testemunho de renovação cultural que se processa hoje em Inglaterra. Poderá o leitor discutir esta ou aquela atitude (...) - poderá inclusive achar um certo grau de irritação em algumas observações, mas não deixará de reconhecer quanto de vitalidade, de arejamento de perspectivas, de desejo de participação, de inconformismo perante a entronização de fórmulas gastas aqui se patenteia.
}

Augusto Sobral (24 anos) era um jovem estudante de arquitectura e um amador de teatro (com Fernando Amado de 1956 a 58) e, ocasionalmente, cenógrafo. Em 1961 escreve 0 consultório e, em 1962, 0 borrão, duas peças em um acto "em que Tchekov e Raúl Brandão se encontram com Beckett e lonesco" (Rebello 1984: 130). Sobral insistirà na sua dramaturgia e, em 1964, verá proibida a sua peça 
Os degraus, uma versão moderna do mito de Prometeu em que os valores do regime fascista eram problematizados.

Fiama Hasse Pais Brandão (24 anos) era uma estudante universitária que colaborava com diversos jornais. Por aquela data, ultimava a publicação da peça Os chapéus-de-chuva que receberia o Prémio Revelação da Sociedade de Escritores e Compositores Teatrais, "em que o individualismo anarquista dos textos anteriores evolui no sentido de um propósito de intervenção no processo histórico em curso" (Rebello 1984: 51). Depois disso, escreveria ainda crítica teatral e estaria ligada ao grupo de teatro da Faculdade de Letras de Lisboa que daria origem ao Teatro da Cornucópia. Também estará ligada ao Teatro Experimental do Porto e participará nos seminários de Adolfo Gutkin, em 1970. Em 1974, será uma das fundadoras do Grupo Teatro Hoje.

José Estevão Sasportes (25 anos) também era colaborador de jornais culturais, como crítico de teatro e de dança.

Publicava, então, vários ensaios sobre dança, criando, mais tarde, obras de referência nesta área, tais como História da dança em Portugal (1970) e Pensar a dança (1983).

Maria Teresa Horta (24 anos) colaborava também com vários periódicos, mas era essencialmente uma poetisa. Publicou na Poesia 61 e, em 1972, será uma das chamadas "Três Marias" (com Maria Isabel Barreno e Maria Velho da Costa), autoras da polémica experiência romanesca Novas cartas portuguesas, considerada pelo regime como ofensiva, imoral e pornográfica.

Formalmente, o traço estruturante do volume antológico é uma forte relação com o teatro dito do absurdo e uma ênfase nas potencialidades líricas do drama. Ainda que as cinco peças sejam acompanhadas por um sinuoso comentário político.

O general, de Artur Portela, é escrito com uma veia humoristica e ocupa-se de um líder sul-americano que está debaixo do ataque de forças revolucionárias. Durante esse ataque, o pintor que Ihe faz o retrato abdica subitamente da sua atitude reverencial quando descobre que este estranho general é um amante de música jazz, "que tem uma discoteca e que distingue Armstrong de Miles Davis" (26). Dando voz a uma ideia geral, o pintor descredibiliza a força do líder alegando que a música jazz é "uma planta venenosa que cresce no seu peito blindado" (27). Uma vez liberto da música e após destruir todos os seus discos, este General recebe o líder da Oposição Moderada, enquanto, nas ruas, a revolução armada se aproxima. À medida que o perigo aumenta, surge um representante americano que procura urânio. Na iminência de perder o poder, o General foge em direç̧ão ao exílio, deixando o país entregue aos interesses estrangeiros e às forças revolucionárias. Esta bizarra caricatura de Portugal surpreende pelas referências abertas ao regime salazarista. Ainda que seja uma representação bem-humorada, irónica e fársica das reais condições de vida, a sua crítica era óbvia, parodiando as políticas interna e externa portuguesas.

O borrão, de Augusto Sobral, deve o seu ímpeto à dramaturgia de Beckett e de lonesco. A situação é elíptica: depois de uma longa conferência, um Conferente e um Presidente acabam sozinhos com um Velho que, acidentalmente, faz um borrão sobre o seu nome num cartão. Tudo isto contribuirá para um estado de grande ansiedade, escalando até à morte do Velho. Nos diálogos, esta personagem apresentar-se-á como viúvo e como um guarda-livros reformado que encontra nas conferências uma boa maneira de convívio. 0 tema esconde uma reflexão sobre a luta dos intelectuais e artistas de toda espécie que são objecto de censura em sociedades vigiadas.

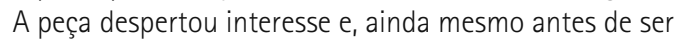
publicada nesta antologia, foi estreada pelo Cénico de Direito com encenação de Morais e Castro (em 1961), um encenador com ligações ao Partido Comunista Português; e foi mais tarde apresentada no Festival de Nancy

Em O museu, Fiama Hasse Pais Brandão apresenta uma visita ao museu de Antropologia Histórica em três cenas. As primeiras duas, intituladas, respectivamente, "Os bons sentimentos" e "Os Maus sentimentos", mostram quadros em que um Cicerone nos acompanha na visita a um Alto Magistrado e a um Criado. 0 tom é absurdista e carregado de segundos sentidos. No quadro final, há um Banquete; durante a refeição, um grupo de convidados conversam evasivamente e sem uma clara relação dialógica. Discutem alegremente diversos assuntos para concluir: 
"Já não se pode respirar aqui. Todos fechados numa sala tão pequena. / É preciso sair daqui. É necessário a liberdade. I Já estamos fartos. / Sujeitámo-nos a ficar aqui tempo demais. / Vamo-nos embora todos. / Embora. / Já não é sem tempo" (77).

A peça de José Sasportes, Funerais: Uma fantasia macabra, é uma divertida distopia sobre o poder. Após a morte de um Patrão, surge um cortejo fúnebre constituido por Acompanhadores, uma Velhinha, um Senhor de Luto, Carregadores e um Professor de Botânica. Este lamento será o motivo para destilar alguns costumes do Portugal de então, tais como o provincianismo, o apelo à emigração e, muito particularmente, o retrato de uma sociedade assente em tradições antigas e regida por velhos. Mais uma vez, os diálogos são evasivos e extremamente líricos, aproximando-se quer do drama poético quer do teatro do absurdo

0 delator de Maria Teresa Horta é, provavelmente, o texto mais incisivo e o mais amadurecido do volume. A poesia aqui é menos presente e esta peça curta é um bom exemplo do realismo socialista na dramaturgia portuguesa. Num cenário naturalista, um grupo de jovens revolucionários prepara um ataque a um regime totalitário. Entretanto, a suspeita de que existirá um delator entre o grupo aumenta. Esta intriga simples será o veículo para discutir a verdadeira natureza dos motivos revolucionários e os projectos de futuro. A dada altura, um dos personagens, Jaime, diz:

Uma revolução não se faz por desporto ou heroísmo, Miguel. Na revolução, cada um de nós só conta num conjunto, nunca individualmente. Não se faz o que gostamos, mas o que for melhor para essa revolução. Queres a liberdade, a razão, o direito, apenas para ti?" (109)

Inês, a personagem central, uma jovem mulher que simboliza a honestidade e a pureza dos ideais revolucionários, perante a destruição do seu grupo, grita:

Eu não quero revoluções para me entreter, nem colaboro nelas por obrigação, amo-as neste país, agora, porque há homens que precisam delas, aqui. Apenas uma e tudo poderia ser diferente... Não as provoco sem serem necessárias nem fujo quando é necessário lutar! (127)

Este texto mereceria, certamente, da parte dos agentes de censura alguma atenção. É por isso que, tal como recorda a autora, foi representado apenas duas vezes por um grupo de amadores do Bairro do Castelo, Lisboa, em 1964. Eram acções pequenas, locais e subversivas: encenar peças, debater politica, publicar antologias, tudo contribuía para um esforço global de renovação cultural e ideológica.

Apesar do pouco sucesso que estas peças acabarão por ter no que diz respeito à sua visibilidade em palco, motivarão, aquando da sua publicação, recensões solidárias e, sobretudo, inspirarão um debate sobre o novo teatro em Portugal. Ainda que João Gaspar Simões tenha recebido duramente os textos, Artur Ramos (com Paulo Renato) organizará um debate com os autores que publicará no Jornal de letras e artes (31 de Janeiro de 1962). Os autores discorrem sobre os motivos revolucionários de cada um dos textos, sobre a sua escrita teatral em diálogo com o actor e o encenador. No final, questionados sobre a qualidade das peças, Ramos responderá: "Considero A rotativa, de Portela, superior a 0 general, da peça da Fiama não gosto e a do Sasportes está no limite. A da Maria Teresa Horta considero-a um esboço imperfeito de uma peça grande. A peça do Sobral já foi apresentada". Paulo Renato, perante a mesma questão articula: "Li-as mais do ponto de vista do encenador. Gostaria de fazer uma experiência. Como actor, nenhuma me interessou". De resto, vários críticos se pronunciaram sobre a antologia, ora louvando a iniciativa, ora identificando algumas fragilidades nas peças. Álvaro Salema escreveria que "o teatro que se representa no volume é "novissimo" na idade. Mas, em face dele, parece prematuro falar em 'novíssimo teatro português'" (Diário de notícias, 22 de Agosto de 1962). Urbano Tavares Rodrigues analisa as peças buscando-Ihes a marca da renovação e, essencialmente, das transformações próprias do teatro jovem: "tal transformação pode ser ao nivel social e moral: a transformação de uma mentalidade, a de uma concepção 


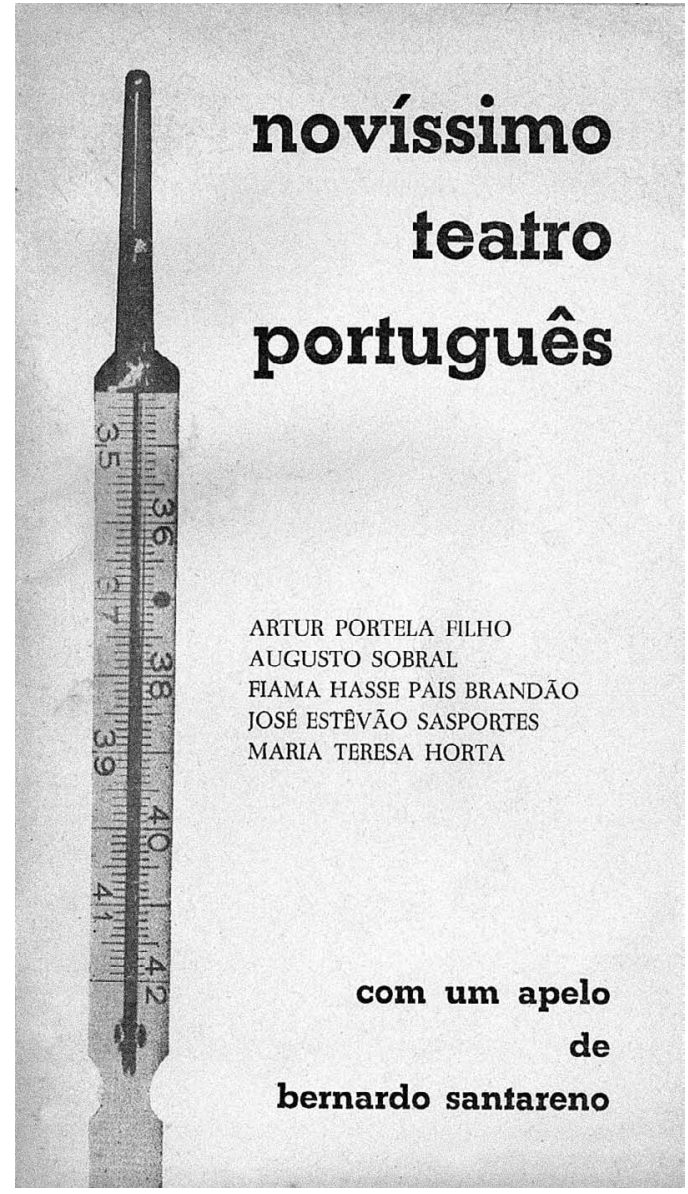

da vida ou da sensibilidade, da forma como se vêem, como se recebem e se julgam sensorialmente as coisas. E isto significa mudança de estilo" (Jornal de letras e artes, 13 de Junho de 1962). António Quadros descobre nesta antologia "peças de tipo experimental nas quais os seus autores ensaiaram processos, formas de diálogo, estilos. Pode dizer-se que nenhum se impõe por si mesmo, mas todos revelam qualidades, sobretudo virtualidades" (Diário popular, 3 de Maio de 1962). Dórdio Guimarães distanciase daqueles que consideram que a antologia "se divorcia na totalidade de todas as características de teatro (?)[sic], apenas se limitando em ser um pretensioso conjunto de textos literários, proclamando uma absurda nova técnica cénica (?) de muito má qualidade e de impraticável encenação", para considerar que "o que há de mais válido e meritório (...) é a tentativa de revalidação de certos elementos funcionais de teatro, a reacção a um marasmo tradicionalista que infelizmente achaca e adormece muitos objectivos de existência. Esse impulso reactor é a [sua] principal e mais útil qualidade" (Diário popular, 12 de Julho de 1962).

Bernardo Santareno, no prefácio do volume, de uma maneira algo conciliatória, explica:

0 teatro de hoje (...) decide-se por um de dois caminhos fundamentais, ou hesita na encruzilhada de ambos. Uma destas vias é seguida pelos dramaturgos que, observando a vida social que os rodeia, dela dão testemunho "interessado" (...). 0 segundo caminho por onde se processa o teatro moderno é percorrido por aqueles dramaturgos que, fora da zona de tensão criada por uma qualquer ideologia (...) se deixam afundar, segundo o peso da gravidade psicológica dos seus seres solitários, abandonados de toda a sociabilidade autêntica: estes realizam a descida aos infernos (...). (5)

\section{Mais adiante, concretiza:}

[0] teatro português não pode deixar (...) de percorrer um destes dois caminhos: por isto mesmo, ele não poderá ser outra coisa que não seja denúncia em primeiro lugar, e depois, esperança político-social (ou religiosa) ou contemplação desesperada do absurdo. (7)

Terminando com um apelo aos censores: "Amem um pouco mais as nossas tentativas de teatro" (9). Não consta que 0 amor fizesse parte da agenda dos agentes censores, mas ainda assim ficava a nota de que estas tentativas de renovação teatral, neste particular, protagonizadas por jovens, reclamavam a sua quota-parte num mundo que Ihes era vedado mas que teimosamente reivindicavam.

\section{Referências bibliográficas}

REBELLO, Luiz Francisco (1977), Combate por um teatro de combate, Lisboa, Seara Nova.

-- (1984), 100 Anos de teatro português (1880-1980), Porto, Brasilia Editora.

MARTINS, Armando (1951), O teatro moderno, Porto, Livraria Simões Lopes. REIS, Carlos (1983), O discurso ideológico do neo-realismo português, Coimbra, Almedina.

VILAÇA, Mário (1967), "Panorama do teatro português contemporâneo", in Teatro contemporâneo: Problemas do jogo e do espírito, Coimbra, Vértice.

RIBEIRO, Ilidio (org.) (1962), Novissimo teatro português (O general, de Artur Portela Filho; O borrão, de Augusto Sobral; 0 museu, de Fiama Hasse Pais Brandão; Funerais, de José Estevão Sasportes; e 0 delator de Maria Teresa Horta), prefácio de Bernardo Santareno, Lisboa, Ao Sol.

OSBORNE, John, LESSING, Doris, WILSON, Colin, et al. (1963), Depoimentos dos "Angry Men", trad. Artur Portela Filho, Lisboa, Editorial Presença. 